\title{
Antibiotic stewardship program in Pakistan: a multicenter qualitative study exploring medical doctors' knowledge, perception and practices
}

Muhammad Atif ${ }^{*}$ (D), Beenish Ihsan¹, Iram Malik, Nafees Ahmad², Zikria Saleem³, Azka Sehar ${ }^{1}$ and Zaheer-ud-Din Babar ${ }^{4}$

\begin{abstract}
Background: The emerging threat of antibiotic resistance is growing exponentially and antibiotic stewardship programs are cornerstone to fight against this global threat. The study aimed to explore the knowledge, perspectives and practices of physicians regarding various aspects of antibiotic stewardship program including antibiotic stewardship activities, rational use of antibiotics, antibiotic resistance, prescribing practices and factors associated with these practices.

Methods: In this qualitative study, a total of 17 semi-structured, in-depth interviews with doctors of three tertiary care public sector hospitals in Bahawalpur and Rahim Yar Khan were conducted. The convenient sampling method was adopted to collect the data and the saturation point criterion was applied to determine the sample size. Thematic analysis approach was used to draw conclusions from the data.

Results: The analysis of data yielded five themes, 12 subthemes and 26 categories. The themes included, (i) perception about antibiotic use and antibiotic stewardship, (ii) antibiotic prescription practices, (iii) antibiotic resistance, (iv) limited strategies adopted by hospital administration to ensure quality and safe distribution of antibiotics, (v) implementation of antibiotic stewardship program: barriers, suggestion and future benefits. Doctors had misconceptions about the rational use of antibiotics. The perception regarding antibiotic stewardship programs was poor. Moreover, very few activities related to ASP existed. The participants gave many suggestions for successful implementation of ASP in order to reduce the burden of antibiotic resistance, including development of guidelines for the use of antibiotics, strict legislation regarding use of antibiotics, active participation of healthcare professionals and awareness program among general public about the use of antibiotics.

Conclusion: This study concluded that poor knowledge of doctors regarding ASP, non-existence of antibiogram of hospital and lack of rules for the safe use of antibiotics were the main driving factors associated with irrational antibiotic prescription practices and development of AR.
\end{abstract}

Keywords: Antibiotic stewardship, Antibiotic resistance, Rational use, One health

*Correspondence: pharmacist_atif@yahoo.com; muhammad.atif@iub.edu.pk

'Department of Pharmacy Practice, Faculty of Pharmacy, The Islamia

University of Bahawalpur, Bahawalpur, Pakistan

Full list of author information is available at the end of the article

(c) The Author(s). 2021 Open Access This article is licensed under a Creative Commons Attribution 4.0 International License, which permits use, sharing, adaptation, distribution and reproduction in any medium or format, as long as you give appropriate credit to the original author(s) and the source, provide a link to the Creative Commons licence, and indicate if changes were made. The images or other third party material in this article are included in the article's Creative Commons licence, unless indicated otherwise in a credit line to the material. If material is not included in the article's Creative Commons licence and your intended use is not permitted by statutory regulation or exceeds the permitted use, you will need to obtain permission directly from the copyright holder. To view a copy of this licence, visit http://creativecommons.org/licenses/by/4.0/ The Creative Commons Public Domain Dedication waiver (http://creativecommons.org/publicdomain/zero/1.0/) applies to the data made available in this article, unless otherwise stated in a credit line to the data. 


\section{Background}

Antibiotics are lifesaving drugs, and more than half of the hospitalized patients receive antibiotics $[1,2]$. According to a study, global consumption of antibiotics increased by $65 \%$ between 2000 and 2015, and this increase was driven by increased consumption in lowand middle-income countries (LMICs). During the same time frame (i.e., 2000 to 2015), the total amount of antibiotics consumed in high income countries (HICs) increased marginally by $6 \%$ (i.e., 9.7 to 10.3 billion defined daily dose (DDD)), whereas in LMICs, antibiotic consumption increased $114 \%$ (i.e., 11.4 to 24.5 billion DDDs) [3]. In 2015, the LMICs with the highest consumption of antibiotics were India, China and Pakistan [3, 4]. Alarmingly, between 2000 and 2015, antibiotic consumption increased $65 \%$ (i.e., 0.8 to 1.3 billion DDDs) in Pakistan [3].

Over the past few years, unnecessarily overuse of antibiotics has led to the emergence of multidrug resistant (MDR) bacterial strains making them ineffective [5-7]. According to the Centers for Disease Control and Prevention (CDC), MDR bacteria cost 23,000 lives annually [8]. Alarmingly, antibiotic resistance (AR) will cause 10 million deaths by 2050, if timely measures are not taken [9]. Besides the development of MDR bacterial strains, inappropriate use of antibiotics negatively influences patients' lives by increasing the length of hospitalization and out-ofpocket expenses, and decreasing quality of life of patients. Moreover, it leads to the financial burden on a healthcare systems [10-16]. Antimicrobial Stewardship involves adopting systematic measures to optimize antimicrobial use, decrease unnecessary antimicrobial exposure and to decrease the emergence and spread of resistance. Many developed countries, such as, Colombia, the United States (US), Australia, South Africa, and the United Kingdom (UK), have developed and successfully implemented different approaches to halt the spread of AR [17]. Regardless of having a high prevalence of AR, LMICs struggle to adhere to antibiotic stewardship programs [18] owing to limited resources [19].

The main factors increasing rates of MDR infections in Pakistan include the unwarranted use of broad spectrum antibiotics as well as insufficient infection prevention and control (IPC) and antibiotic stewardship polices [15, 20-22]. Consequently, a surge in AR has been seen over the past years, which makes drug therapy complex for infectious diseases like typhoid, tuberculosis, etc. [20, 23]. In 2016, the Medical Microbiology \& Infectious Disease Society of Pakistan adopted the guidelines provided by the World Health Organization (WHO) Global Action Plan (GAP) to combat antimicrobial resistance, and started antibiotic stewardship program (ASP) in hospital settings [24-26]. The aim of this GAP was to halt the progression of antimicrobial resistance by initiating interventions at various levels of healthcare such as institutions, prescribers, policy makers and patients [27]. Moreover, this program also aimed to improve the clinical outcomes among the patients on antimicrobial therapy [27]. A few earlier studies from Pakistan showed that despite the efforts to implement ASP in Pakistani hospitals, the antibiotic use practices were inappropriate and the physicians were least aware about this program [21, 28-31]. The most common antibiotic stewardship activities currently practiced in Pakistani hospitals include clinical pharmacy services, the use of antimicrobial prescribing guidelines, consultation services, use of drug and therapeutics committees to approve antimicrobial prescribing, regular audit by doctors on antimicrobial prescribing and use of a restricted formulary for antimicrobial. Nevertheless, the aforementioned studies were conducted in Lahore which is the capital of the Punjab province and located in the northern part of the Punjab province of Pakistan, while similar studies from the southern Punjab are scarce. Owing to relatively better healthcare infrastructure in the capital city of Punjab, the findings of the abovementioned studies cannot be extrapolated to the whole of Punjab. Moreover, perceptions of physicians about ASP, AR and antibiotic could vary from institution to institution. Therefore, a multicenter qualitative study was conducted with the aim investigate ASP in the public sector hospitals of the southern Punjab province of Pakistan. The study emphasized on knowledge, perspectives and practices of doctors regarding various aspects of ASP including the rational use of antibiotics, antibiotic resistance, prescribing practices and factors associated with these practices. The findings of this study will help to understand the perspective of doctors about antibiotic prescription practices and their perception about ASP. This will also help the policymakers understand the barriers associated with the successful implementation of this program in Pakistani hospitals.

\section{Method}

\section{Study setting}

In Pakistan, healthcare in the country is regulated by the Ministry of National Health Services Regulation and Coordination and the healthcare delivery system is comprised of primary, secondary and tertiary care [32]. Primary care is provided by the basic health units and the rural health centers and lady health workers. The district headquarter hospitals and the tehsil headquarter hospitals provide secondary care [32]. Tertiary care is provided by the tertiary hospitals, mainly situated in highly populated and developed parts of the country [32]. Overall, the Pakistani health sector is confronted 
with an imbalance in the number and deployment of healthcare workforce, and inadequate allotment of resources across different tiers of healthcare [33]. There are 132,227 hospital beds, 1279 hospitals, 5671 dispensaries, 5527 basic health units, and 747 maternity and child health centers in the country [34]. To serve the healthcare needs of a population of more than 207 million citizens, there are 233,261 doctors, 24,930 dentists, 112,123 nurses and 20,565 lady health workers in the country [34].

This study was conducted in two cities of the Punjab province of Pakistan i.e., Bahawalpur and Rahim Yar Khan. The Bahawal Victoria Hospital (BVH), Bahawalpur (1600 plus bedded facility) and the Civil Hospital, Bahawalpur (400 bedded facility) are two tertiary care hospitals located in the district of Bahawalpur [13, 35], and the Sheikh Zayed Hospital, Rahim Yar Khan (1700 bedded facility) is the only tertiary care hospital located in the district of Rahim Yar Khan. The provision of suboptimal ASPs in these hospitals are limited to the use of antimicrobial prescribing guidelines, delivery of infectious diseases consultation services, use of drug and therapeutics committees to approve antimicrobial prescribing, regular audit by prescribers and use of a restricted formulary for antimicrobial [12]. Medical doctors working in these three hospitals were invited to participate in the study.

\section{Study design and study participants}

A qualitative study design [36] was adopted to evaluate the knowledge and perception of doctors about ASP and related activities in their hospitals. The doctors who consented to participate in the study were face-to-face interviewed using semi structured interview guide. Doctors having working experience of $\geq 2$ years were included in this study. The interviews were conducted from the doctors having different specializations to understand the views of doctors from different specialties.

\section{Interview schema development}

The interview schema was developed after comprehensive literature review to answer the research questions (Additional file 1) [36, 37]. The schema was developed keeping in mind the inductive approach for data analysis because the creation of preliminary codebook to guide deductive analysis [38] was not possible due to unavailability of data on our research question, especially from Southern Punjab (study setting). Therefore we included open-ended questions for in-depth exploration of various aspects of the ASP. Semi structured interview schema was pilot tested in two doctors to ensure its validity, and uniformity of the content. It helped in better understanding of study's instrument. The results of pilot interviews were not included in the final analysis. Final pilot tested interview guide included 12 questions with further sub questions to evaluate the knowledge of doctors about ASP and its related activities in hospitals, reasons of unnecessary use of antibiotics and their perspective on situation of resistance.

\section{Data collection}

The data were collected in July and September, 2019. The participants were selected by two step sampling processes. In the first step, purposive sampling technique was adopted with the aim to ensure information richness and representation of the population [39]. Resultantly, a list of 54 knowledgeable experts having work experience of $\geq 2$ years and working in different specialties (where antibiotics are frequently prescribed e.g., kidney ward, emergency department, paediatrics etc.) was generated. Thereafter, considering the busy schedules of both the physicians and the research team, we proceeded with the convenient sampling. Participants were approached between $8 \mathrm{am}$ to $2 \mathrm{pm}$ in hospitals and those who consented to participate were interviewed at a time and place that was agreeable to both parties. BI and AS were involved in data collection. They had prior training in qualitative studies before data collection. All interviews were audio recorded and conducted in Urdu (national language of Pakistan). The sample size was determined by applying the saturation point criteria [40, 41]. Two additional interviews were conducted to confirm the saturation in emergent themes.

\section{Data analysis}

All audio-taped interviews were transcribed verbatim. The written transcripts were translated into English and read several times by BI and IM to familiarize and deeply understand the data. Forward-backward translation method was applied on some of the transcripts to ensure the accuracy of translation [42]. The data were analyzed using thematic content analysis. Standard method of the inductive thematic analysis was followed [36, 43]. First of all, all the relevant words and sentences were highlighted and codes were assigned to them. After coding the lines from the interviews, the data were organized into relevant categories. The categories were then reduced to draw final themes and subthemes [44, 45]. Themes were decided to answer the research questions posed. Suitable quotations were added for the understanding of themes and subthemes. MA led the data analysis process and gave the final verdict in case there was any disagreement among the authors. We followed Consolidated Criteria for Reporting Qualitative Studies (COREQ) during the study process [46]. 


\section{Results}

\section{Participant's characteristics}

A total of 17 doctors were interviewed. Though, the saturation in emergent codes and themes was achieved after 15 interviews, but two additional interviews were conducted to confirm that the saturation was achieved. Four doctors did not agree to participate in the interviews during the convenient sampling stage due to assorted reasons, such as lack of interest in the study, fear of authorities and busy work schedule (response rate $=$ $80.9 \%$ ). The duration of interviews ranged from 20 to 30 min with an average duration of $25.5 \mathrm{~min}(\mathrm{SD}=3.83)$. The participants had minimum experience of two years and maximum experience of 10 years. Eleven participants were male and six were female. Characteristics of the participants are given in Table 1.

The thematic analysis of the data yielded five themes and 12 subthemes. The themes included: perception about antibiotic use and ASP, antibiotic prescription practices, AR, limited strategies adopted by hospital administration to ensure quality and safe distribution of antibiotics, and implementation of ASP: barriers, suggestion and future benefits.

\section{Theme 1: perception about antibiotic use and antibiotic stewardship}

To understand the familiarity of doctors about the terms related to antibiotic use, they were asked about how they perceive the term rational use. Most of the study

Table 1 Characteristics of the respondents

\begin{tabular}{llll}
\hline Respondent & Sex & Specialization & Interview duration \\
\hline Doctor 1 & Female & Pulmonology & 32 \\
Doctor 2 & Male & Medicine & 29 \\
Doctor 3 & Male & Pulmonology & 22 \\
Doctor 4 & Female & Pediatrics & 27 \\
Doctor 5 & Male & Pediatrics & 22 \\
Doctor 6 & Female & Gynecology & 23 \\
Doctor 7 & Male & Cardiac surgery & 30 \\
Doctor 8 & Male & Nephrology & 28 \\
Doctor 9 & Male & Nephrology & 27 \\
Doctor 10 & Male & Pediatrics surgery & 25 \\
Doctor 11 & Female & Burn unit & 25 \\
Doctor 12 & Male & Nephrology & 20 \\
Doctor 13 & Male & Cardiac surgery & 30 \\
Doctor 14 & Male & Pediatrics & 24 \\
Doctor 15 & Female & Pediatrics & 30 \\
Doctor 16 & Female & Pediatrics & 20 \\
Doctor 17 & Male & Pediatrics & 20 \\
Mean duration & & & $\mathbf{2 5 . 5}$ min \\
\hline
\end{tabular}

participants had inadequate knowledge about rational use of antibiotics (12 out of 17 respondents) as they had misconception that use of broad spectrum antibiotics is called empirical therapy and that it was rational use. All respondents (17 out of 17 respondents) agreed that irrational use of antibiotics was a problem in Pakistan. ASP was the term that most of the doctors were not familiar with. Doctors who were familiar with the term were those who had work experience at large private sector hospitals in Karachi and Lahore (3 out of 17 respondents) (Table 2).

\section{Theme 2: antibiotic prescription practices}

Broad spectrum antibiotics were considered as better treatment option by the doctors ( 8 out of 17 respondents). Moreover, broad spectrum antibiotics were prescribed as prophylactic agents to patients for nosocomial infections. Patient's poor financial status and limited resources in public sector hospitals were highlighted by nine doctors as main reasons why culture tests were not performed. Unreliable laboratory reports were highlighted (2 out of 17 respondents) as a reason for not sending specimens for cultures (Table 3).

\section{Theme 3: antibiotic resistance}

Most of the respondents (15 out of 17) stated that situation of AR is alarming in Pakistan. The doctors highlighted frequent use of antibiotics for minor ailments (9 out of 17 respondents) and as one of the main reasons of AR. Six out of 17 respondents stated that poor compliance and improper dosing contribute to already existing problem of antibiotic resistance. Lack of doctors' experience (2 out of 17) and quacks working as doctors in remote areas of Pakistan (8 out of 17 respondents) were also reported as contributing factors that aggravated the problem of resistance. Four out of 17 doctors described that antimicrobial resistance leads to increase in out-of-pocket expenses of patients (Table 4).

Table 5 describes the most commonly known resistant bacterial species reported by the study participants. The study participants stated that, mostly, gram negative bacterial species were resistant to commonly used antibiotics.

\section{Theme 4: limited strategies adopted by the hospital administration to ensure quality and safe distribution of antibiotics}

Most of the respondents agreed that there is no proper system to ensure the safe use of antibiotics (15 out of 17 respondents). They agreed that, although, policies and rules exist to ensure the quality and safe distribution of antibiotics but they are 
Table 2 Perception about antibiotic use and antibiotic stewardship: themes, subthemes, categories and exemplar quotations

\begin{tabular}{lll}
\hline Subthemes & Categories & Quotations \\
\hline Familiarity & Empirical therapy was perceived as & $\begin{array}{l}\text { R2: Proper use or rational use here is, if we suspect infection we start antibiotic even if we are } \\
\text { with terms } \\
\text { not sure the infection is bacterial or viral. It is a tertiary care hospital so some time we do } \\
\text { perform microbiology tests but not commonly. We suspect we prescribe the antibiotic which } \\
\text { can work for everything. }\end{array}$ \\
& $\begin{array}{l}\boldsymbol{R} \mathbf{1 1}: \text { Basically our hospital is teaching hospital we give antibiotic on proper time and with } \\
\text { proper dose. We never give antibiotic without its need. Sometimes we do when have to give it } \\
\text { prophylactically; patient is admitted and has exposure with infections. Here antibiotics are used } \\
\text { rationally. }\end{array}$
\end{tabular}

Irrational use of antibiotics

Only few were familiar with the term "antibiotic stewardship" Majority were not familiar with the term "antibiotic time-out"
R13: We give medicine on patient demand it happens. We don't go for cultures and blindly give triple therapy or a broad spectrum antibiotic.

R3: It is multidisciplinary programme, consist first starting from of physicians, pathologist/ microbiologist and pharmacologist. They work together on incidence and prevalence of infection and on the basis of it form an antibiogram and then proper empirical treatment is decided and proper use of antibiotics takes place.

R4: I don't know anything about that programme. And that kind of system is not practiced here.

R15: I don't know.it is very difficult word? What does it mean? And nothing like this is practiced here or known about. usually not followed. However, some study participants pointed out different strategies that were adopted to ensure safe use of antibiotics. Two out of 17 respondents stated that if a medicine was showing some adverse drug event, it was reported to hospital pharmacist. One respondent stated that pharmaceutical products containing antibiotics were sent to drug testing laboratory to check whether these meet quality standards. One respondent stated that one positive strategy to ensure rational use of antibiotics is to prescribe antibiotics from hospital essential list (Table 6).
Theme 5: implementation of antibiotic stewardship programme: barriers, suggestions and future benefits Multiple reasons were highlighted by the respondents that were considered as barriers for successful implementation of antibiotic stewardship programme. Fifteen out of 17 respondents stated that no educational programme or awareness campaign existed to educate doctors about antibiotic stewardship. Lack of hospital antibiogram was considered as a major barrier which hindered the implementation of antibiotic stewardship program (10 out of 17 respondents). The respondents

Table 3 Antibiotic prescription practices: theme, subthemes, categories and exemplar quotations

\begin{tabular}{lll}
\hline Subthemes & Categories & Quotations \\
\hline Use of broad & - Provides good cover & $\mathbf{R 3 :}$ When you don't know which microorganisms it is, you fire all the guns and it's safe. \\
spectrum antibiotics & - Prophylactic use & $\begin{array}{l}\mathbf{R 4} \text { : We give broad spectrum to make sure that the patient does not acquire any hospital } \\
\text { acquired infection. }\end{array}$
\end{tabular}

Why bacteriology is Patient perspective not performed? $\quad$ Affordability

Hospitals perspective

- Limited resources

- Diagnosis based on clinical judgement

- Lack of inter department communication

- Unreliable laboratory test results

Laboratory investigations performed
Before prescribing antibiotics - Only complete blood count as base line investigation

- Culture tests were uncommon

Investigations adopted to check 'antibiotic timeout'

- Improvement in apparent condition

- Check leucocyte count

- No specific investigations for 'antibiotic timeout'
R1: We live in a country with limited resources. We know that patient has, for example, respiratory or urinary tract infection, there might be known organisms and these antibiotics are effective so we will not tease a person with limited financial resources.

R4: Everything is not diagnosed on base of culture sensitivity tests there are many clinical signs e.g. pneumonia, Gl problem we start the treatment and if problem is not solved we go for further investigations and we have limited resources so we cannot send cultures for every patient.

R10: Our bad scenario is that our labs are not up to date, you can conduct the same test from 3 different laboratories and all of the results will be different and culture tests reports take more than 10 days so it is very time consuming.

R1: In government setup, we carry out basic investigations which indicate patient is having infection but what sort of infection what sort of organism he or she is having we cannot say anything about it.

R11: No trend of culture tests. We only do it if condition of patient is worse and no medicine is working against it.

R5: Mainly improvement of symptoms, and then urine culture, blood tests showing improvement in total leucocyte count shows medicine is effective. R3: In severe cases we have to give empiric treatment and it is recommended but after $72 \mathrm{~h}$ if you are asking about whether we check responses, we usually don't. 
Table 4 Antibiotic resistance: themes, subthemes, categories and exemplar quotations

\begin{tabular}{|c|c|c|}
\hline Subthemes & Categories & Quotations \\
\hline Alarming situation & $\begin{array}{l}\text { Escalating resistance against } \\
\text { various infectious disease }\end{array}$ & $\begin{array}{l}\text { R3: Drug resistance is the major problem. In quinolone here drug resistance is up to } 48 \% \\
\text { and this is very alarming. While sitting in South East Punjab, even in tuberculosis } \\
\text { resistance has increased a lot. } \\
\text { R4: I am working in neonatology unit most of the neonates are resistance to most of the } \\
\text { broad spectrum antibiotics. if we see culture reports you can see that bacteria are } \\
\text { resistant to } 90 \% \text { drugs. }\end{array}$ \\
\hline \multirow[t]{6}{*}{ Reasons of resistance } & $\begin{array}{l}\text { Frequent use of antibiotics for } \\
\text { minor ailments }\end{array}$ & $\begin{array}{l}\text { R2: There is no need of antibiotics in viral infection like flu, and viral diarrhea in children, } \\
\text { but antibiotics are used and prescribed for such ailments. }\end{array}$ \\
\hline & $\begin{array}{l}\text { Demand of antibiotic by patient } \\
\text { for minor ailments }\end{array}$ & $\begin{array}{l}\text { R4:Doctor just give them painkiller and then they ask why you have not given us } \\
\text { antibiotic. }\end{array}$ \\
\hline & $\begin{array}{l}\text { Improper dosing and poor } \\
\text { compliance }\end{array}$ & $\begin{array}{l}\text { R6: Patient does not take medicine in exact dose and for complete duration. Patients } \\
\text { take it for } 2 \text { or } 3 \text { days and discontinue because of many reasons. }\end{array}$ \\
\hline & Lack of qualified professionals & $\begin{array}{l}\text { R8: I worked in primary healthcare center. There antibiotics are used irrationally } \\
\text { specifically in children by quacks, who are non-qualified and not licensed to prescribe. }\end{array}$ \\
\hline & $\begin{array}{l}\text { Limited number of antibiotics in } \\
\text { public healthcare sector }\end{array}$ & $\begin{array}{l}\text { R3: In quinolone if we require ciprofloxacin we sometimes get moxifloxacin. And in the } \\
\text { same way we do not get the required dosage form. Dose cannot be adjustment. We } \\
\text { have not many options available. }\end{array}$ \\
\hline & $\begin{array}{l}\text { Lack of experience drives } \\
\text { inappropriate use }\end{array}$ & $\begin{array}{l}\text { R3: There is no guidance for health care professionals. Junior doctors (having little or no } \\
\text { experience) use broad spectrum antibiotics for minor infections. }\end{array}$ \\
\hline \multirow[t]{2}{*}{$\begin{array}{l}\text { Challenges associated with } \\
\text { antibiotic resistance }\end{array}$} & $\begin{array}{l}\text { Threat to effective antibiotic } \\
\text { options for treatment } \\
\text { Expensive drugs are the only } \\
\text { option }\end{array}$ & $\begin{array}{l}\text { R7: In next } 10 \text { years more than } 60 \% \text { antibiotics will become resistant and useless. After } \\
\text { some years it may be impossible to treat patients with antibiotics that are available now. } \\
\text { R9: New antibiotics are costly and new generations are not easily available. }\end{array}$ \\
\hline & $\begin{array}{l}\text { Effect on patient } \\
\text { - Recurrent infection } \\
\text { - Financial burden on patient }\end{array}$ & $\begin{array}{l}\text { R1: Patients suffer financially and ends up having recurrent infection. } \\
\text { R3: Patient remains untreated because we have limited options. Patients cannot afford } \\
\text { to buy purchase new antibiotics from market and they end up having recurrent infection. }\end{array}$ \\
\hline
\end{tabular}

suggested that the government support and strict legislation regarding use and dispensing of antibiotics was important to ensure safe use of antibiotics (4 out of 17 respondents). More than half ( 9 out of 17 respondents) of the respondents stated that general public should be made aware to avoid self-medication of antibiotics, and they must also avoid visiting quacks (Table 7).

Table 5 Organisms for which drug resistance was commonly reported

\begin{tabular}{ll}
\hline Resistant organisms & \\
\hline Gram negative & Salmonella spp \\
bacteria & Pseudomonas aeruginosa \\
& Escherichia coli \\
& Klebsiella pneumoniae \\
& Stenotrophomonas maltophilia \\
& Acinetobacter spp \\
& Haemophilus influenza \\
& Morganella morganii \\
Gram positive bacteria & MRSA (methicillin resistant Staphylococcus \\
& aureus) \\
Acid fast bacteria & Mycobacterium tuberculosis
\end{tabular}

\section{Discussion}

Antimicrobial resistance is an issue that has been increasing globally with an alarming rate making it a huge concern [47]. Many interventions have been introduced to reduce incidence of AR [48, 49]. Such interventions are considered essential part of healthcare settings; one of such is ASP. This is one of the few studies conducted in Pakistan to access the knowledge of doctors about ASP, besides, it also explored the prescription practices of doctors and their views on situation of AR and its contributing factors. The perception of doctors about rational use of antibiotics and ASP was poor. Published papers have shown that physicians rarely improve their prescribing practices unless they have good knowledge and perception about antibiotic use and ASP [50].

Findings of this study revealed that the doctors used to prescribe broad spectrum antibiotics as an empiric therapy. Our participants also agreed that habitual empiric prescribing practices lead to inappropriate use of antibiotics which subsequently lead to AR. These results were similar to studies conducted in Cambodia and Iran that described the similar kind of behavior [51, 52]. Earlier study described that the inappropriate use of antibiotics may lead to prolonged hospital stay, increased cost of treatment, need for additional antimicrobial therapy, 
Table 6 Limited strategies adopted by hospital administration to ensure quality and safe distribution of antibiotics: themes, subthemes, categories and exemplar quotations

\begin{tabular}{|c|c|c|}
\hline Subthemes & Categories & Quotations \\
\hline \multirow[t]{2}{*}{$\begin{array}{l}\text { Reporting } \\
\text { system }\end{array}$} & $\begin{array}{l}\text { Adverse drug event reporting to } \\
\text { hospital pharmacist is minimal }\end{array}$ & $\begin{array}{l}\text { R1:Drug is showing serious side effect, dosage form is not proper, or drug is substandard we } \\
\text { report it to pharmacist but it rarely happens that we report as there is no proper reporting } \\
\text { system. }\end{array}$ \\
\hline & $\begin{array}{l}\text { If medicine is substandard } \\
\text { - Report to company } \\
\text { - Obligatory drug testing to ensure the } \\
\text { quality }\end{array}$ & $\begin{array}{l}\text { R5: There is protocol called recall medicine protocol. We fill the form and report it to company. } \\
\text { And ideally district drug controller should be informed. } \\
\text { R2: Drug testing laboratory for testing quality of antibiotics if we see any problem like even given } \\
\text { in proper dose and medicine is not effective. }\end{array}$ \\
\hline
\end{tabular}

adverse patient outcomes and development of AR [53, 54]. No doubt, selection of antibiotics should be based on the culture and sensitivity results. However, delays in the availability of microbiology reports, lack of trust of doctors on the laboratory reports, burden on the laboratories of public sector hospitals, limited availability of antibiotics in the hospitals and poor financial status of patients compel the doctors to prescribe broad spectrum antibiotics. The same reasons of inappropriate use of antibiotics were highlighted in our study and a study from India [55].

The present study also revealed that the doctors used to prescribe antibiotics in almost all hospitalized patients as a prophylactic measure to counter the nosocomial infections. Similarly, a study from India also revealed that doctors prescribed antibiotics in hospitalized patients to avoid superinfections [56]. Findings of this study also revealed the patients also influenced doctors' prescription by compelling them to include an antibiotic in their prescription to achieve fastest cure. This finding was similar to the studies from Sri Lanka and the UK which explained that the patients influenced that doctors to prescribe antibiotics, even when these were not required $[57,58]$.

A multicounty study conducted in European countries revealed that antibiotic guidelines help doctors in rational prescribing of antibiotics [59]. However, our study findings revealed that antibiotic use guidelines were not available in the hospitals, and the doctors used to prescribe antibiotics based on their clinical experience. The same antibiotic prescribing practices were reported in studies from India and Iran $[52,55]$, while, a study conducted in Saudi Arabia revealed to have antibiotics use guidelines in hospitals [60]. It is a good omen that our

Table 7 Implementation of antibiotic stewardship programme: Barriers, suggestions and future benefits: themes, subthemes, categories and exemplar quotations

\begin{tabular}{|c|c|c|}
\hline Subthemes & Categories & Quotations \\
\hline $\begin{array}{l}\text { Barriers to successful } \\
\text { implementation }\end{array}$ & $\begin{array}{l}\text { Workshops on antibiotic stewardship } \\
\text { were not conducted }\end{array}$ & $\begin{array}{l}\text { R3: There are very few people in this setting who talk about this or know about } \\
\text { this. But no one owns it and its importance is neglected. No awareness } \\
\text { workshop has been conducted regarding this programme in this setting. }\end{array}$ \\
\hline
\end{tabular}

Lack of proper audit system

Lack of updated knowledge for qualified professionals

Unavailability of antibiotic use guidelines and hospital antibiogram

Suggestions

Strict enforcement of ongoing and new legislations

Active participation of health care professionals

Awareness among general public about antibiotic resistance and proper use

Future benefits of antibiotic stewardship programme
Might help in current issue of antibiotic resistance

Helps in rational prescribing
R5: Accessibility to antibiotics is very easy that everybody can prescribe it like dispenser, junior doctors, trainee doctors, etc.

R8: Doctors are prescribing medicines that are not necessary and even those which are no more used in many other countries and are not necessary and no guidance for health care professionals is available.

R9: The hospital did not provide us antibiotic use guidelines.

R15: There is no antibiogram available in hospital to guide us about resistant organisms and treatment options.

R3: Our hospital has no specific guidelines. For bronchitis we follow British Thoracic Society guidelines.

R4: We can implement this programme by bringing policies and it will require a lot of effort and home work. We should also make our public and physicians aware that antibiotics are not those medicines which you should use causally.

R1: General practitioner should be made aware about rational use because patients visit them first. Pharmacist and doctor should collaborate and work together to ensure safe use of antibiotics.

R5: We should educate our public that they should avoid self-medication of antibiotics and should not take it from unqualified professional.

R4: Right medicine will be given to patient.

R7: It will educate doctors about latest guidelines and about resistance of antibiotics and by utilizing that awareness we can save our people from further resistance. 
study participants were aware of the importance of having guidelines and felt that antibiotic prescribing practices could be improved upon availability of guidelines and information on local AR patterns. Likewise in a study from Ireland, doctors reported that the availability of local AR patterns could improve their antibiotic prescribing practices and contribute to improved patient outcomes [61]. Hospital antibiogram helps the doctors to select most effective antibiotic for the patients. However, according to our study participants, hospital antibiogram was not available in their hospitals. A study from the US showed improvements in antibiotic use if an antibiogram existed in a hospital [62]. Findings of this study also revealed that no audits were conducted in their hospitals to check the alarming rise in antibiotic use and AR. While, a study conducted in Kuwait showed audits helped in rational prescribing and prescription of antibiotics according to guidelines [63]. Availability of institutional antibiogram, antibiotic prescribing guidelines, educational sessions, advice from an antimicrobial stewardship team, regular audits and feedback strategies can greatly improve the rational antibiotic prescribing and the same was emphasized in earlier studies from Pakistan [30, 31]. According to a review, online training and mentoring programmes, national guidelines, and social media in stewardship all contributed to the success of antimicrobial stewardship programmes in the UK, the US, South Africa, Australia, and Colombia [17]. Likewise, the effectiveness of antibiotic stewardship interventions was evidenced by a review based on studies from LMICs, which found that all types of antibiotic stewardship interventions improved antibiotic prescribing and clinical outcomes [18]. Despite the limited but wellestablished benefits of ASP, another review indicated that LMICs face resource constraints, making it difficult for them to adopt "a WHO Practical ASP toolkit" in order to develop and sustain ASPs [19].

This study revealed that doctors had no idea about ASP, and it was relatively a new word for them. These findings were similar to an Indian study [55], while a Namibian study showed high awareness about ASP among healthcare professionals, although, it was not implemented with all its core elements [64]. Lack of our participants' knowledge about ASP was either due to lack of training opportunities for them or due to the fact that they did not have any compulsion to attend such seminars. The interviewees also considered that these seminars did not benefit their professional career. Unfortunately, in Pakistan, there is no credit point system that could be added to profile of healthcare professionals. According to the WHO, training on antimicrobial stewardship improve the competency of healthcare professionals for judicious use of antibiotics. For this, the WHO offers courses for the clinicians, for example, "antimicrobial stewardship - a competency-based approach" [65].
This study has few limitations as well. First, a convenient sampling method was used to collect data. In convenience samples, subjects who are more easily accessible to the researcher are more likely to be included and, therefore, not all qualified individuals in the target population have the same opportunity to participate and study results are not much reliable and necessarily generalizable to this population. Though, increasing the sample size in quantitative studies can improve the credibility of convenience samples, but this is difficult in qualitative studies because saturation point criterion is used as redundancy signal. However, considering aforementioned concerns, a mix of purposive and convenience sampling was adopted and we believe that the utilization of purposive sampling in the first phase surpassed any possible concerns associated with convenient sampling and saturation point criteria altogether. Second, our findings cannot be generalized to the whole of Pakistan as these depict the views of doctors working in two main cities of southern Punjab. However, the authors do not expect significant differences across the country, as the same healthcare system has been implemented and regulated throughout the country by the Ministry of National Health Services, Regulation and Coordination. Though this study provides an indication of what is happening in the whole province of Punjab, but there is a need for large scale multi-setting quantitative studies to underline more reliable and impactful country-level situation. Likewise, multi-perspective studies involving regulators, pharmacists, nurses and dispensers are encouraged to improve the antibiotic stewardship activities at each level of healthcare through evidence based recommendations.

\section{Implication of findings on policy and practice}

The strength of the present study is that it highlighted an important issue about which limited data is available from developing countries, for example, Pakistan. In terms of policy, our study findings warrant the need to put legislation to introduce the ASP in hospital settings in Pakistan. Moreover, National Action Plan of Pakistan on AR must be implemented to prohibit irrational use of antibiotics and to implement ASP. In practice terms, there is a dire need regarding training and involvement of doctors in ASP to minimize the surge in the antimicrobial resistance issue. Frequent seminars must be conducted on small and large scale to educate doctors about the benefits of implementing ASP, and warn them to prescribe antibiotics cautiously because of the fact that our study participants imperfectly understood the concept of empirical therapy and ASP. Yet education alone will not be enough, antibiotic prescribing guidelines and local antibiogram must be available in each hospital. In addition, collaborative efforts by all the 
healthcare professionals dealing with human as well as animal patients are needed to adopt "One Health Approach" with the aim to halt the spread of antibiotic resistance at each level. Future large scale interventional studies involving doctors, pharmacists, nurses, veterinary and agricultural experts and health policy makers are also required to assess the impact of ASP on health outcomes and to understand the potential barriers and facilitators for implementation of program.

The study findings will not only aid countries with existing ASPs in forthcoming initiatives, but also those countries that are planning to implement ASPs can gain insight for effective introduction of programme. Specifically, the findings of this study highlight that countries with existing ASPs should focus on awareness and education of healthcare professionals about ASPs protocols, strict compliance with the antibiotic prescribing guidelines, active participation of healthcare professionals, and availability of local antibiogram in each healthcare facility. Whereas, the countries planning to implement ASPs can learn that special attention to the above mentioned aspects is mandatory for an effective introduction of activities. Moreover, the study findings will act as a strong base and impetus for both large scale multi-stakeholder qualitative studies and quantitative studies.

\section{Conclusion}

The study concluded that the doctors working in the public sector hospitals of Pakistan had inadequate knowledge about ASP. There was no proper system in place to ensure the appropriate use of antibiotics. Similarly, local antibiogram data and antibiotic prescribing guidelines were not available in the hospital. There is dire need to implement the strategic objectives of national action plan of Pakistan on AMR in order to mitigate the adverse outcomes of AR in future.

\section{Abbreviations}

ASP: Antibiotic Stewardship Programs; LMICs: Low- and Middle-Income Countries; DDD: Defined Daily Dose; MDR: Multidrug Resistant; CDC: Centers for Disease Control And Prevention; AR: Antibiotic Resistance; IPC: Infection Prevention and Control; GAP: Global Action Plan; BVH: Bahawal Victoria Hospital; COREQ: Consolidated Criteria for Reporting Qualitative Studies

\section{Supplementary Information}

The online version contains supplementary material available at https://doi. org/10.1186/s12879-021-06043-5.

Additional file 1. Interview schema

\section{Acknowledgements}

The authors thank administrative departments of the hospitals for granting permission to undertake this study.

\section{Authors' contributions}

MA: Conceptualization, Methodology, Analysis, Writing - Writing - review \& editing, Supervision. BI: Conceptualization, Writing - original draft, Project administration, Formal analysis, IM: Methodology, Formal analysis, Writing - review \& editing, Supervision. ZS: Methodology, Analysis, Writing - review \& editing. NA: Methodology, Analysis, Writing - review \& editing, Supervision. AS: Conceptualization, Writing - original draft, Project administration, Formal analysis, ZUD: Conceptualization, Methodology, Writing - review \& editing. All authors have read and approved the manuscript.

\section{Funding}

None.

Availability of data and materials

The raw data will be provided upon receiving reasonable request. Please contact corresponding author at pharmacist_atif@yahoo.com

\section{Declarations}

Ethics approval and consent to participate

The ethics approval was obtained from the Pharmacy Research and Ethics Committee (PREC) at the Islamia University of Bahawalpur. In this study, verbal consent was obtained from all the participants before interviews. PREC approved verbal consent procedure. The identity of the respondents was kept confidential to ensure complete privacy. Anonymity of their opinions was confirmed by using codes. The study participants were given the freedom to skip a question or leave the interview at any time during the study. They were also offered to read their interview transcript.

\section{Consent for publication}

$\mathrm{N} / \mathrm{A}$

\section{Competing interests}

The authors declare no conflicts of interests.

\section{Author details}

${ }^{1}$ Department of Pharmacy Practice, Faculty of Pharmacy, The Islamia University of Bahawalpur, Bahawalpur, Pakistan. ${ }^{2}$ Department of Pharmacy Practice, Faculty of Pharmacy and Health Sciences, University of Balochistan, Quetta, Pakistan. ${ }^{3}$ Department of Pharmacy, University of Lahore, Lahore, Pakistan. ${ }^{4}$ Department of Pharmacy, University of Huddersfield, Huddersfield, UK.

Received: 15 October 2020 Accepted: 5 April 2021

Published online: 21 April 2021

\section{References}

1. Versporten A, Zarb P, Caniaux I, Gros MF, Drapier N, Miller M, et al. Global PPSn: antimicrobial consumption and resistance in adult hospital inpatients in 53 countries: results of an internet-based global point prevalence survey. Lancet Glob Health. 2018;6(6):e619-29. https://doi.org/10.1016/\$2214-109X(1 8)30186-4.

2. Saleem Z, Hassali MA, Godman B, Versporten A, Hashmi FK, Saeed H, et al. Point prevalence surveys of antimicrobial use: a systematic review and the implications. Expert Rev Anti-Infect Ther. 2020;(just-accepted).

3. Klein EY, Van Boeckel TP, Martinez EM, Pant S, Gandra S, Levin SA, et al. Global increase and geographic convergence in antibiotic consumption between 2000 and 2015. Proc Natl Acad Sci. 2018;115(15):E3463-70. https:// doi.org/10.1073/pnas.1717295115.

4. Klein EY, Van Boeckel TP, Martinez EM, Pant S, Gandra S, Levin SA, et al. Global increase and geographic convergence in antibiotic consumption between 2000 and 2015. Proc Natl Acad Sci. 2018:201717295.

5. 7 things to know about inpatient, outpatient antibiotic use [https://www. beckershospitalreview.com/quality/7-things-to-know-about-inpatient-outpa tient-antibiotic-use.html].

6. Penesyan A, Gillings M, Paulsen IT. Antibiotic discovery: combatting bacteria resistance in cells and in biofilm communities. Molecules. 2015:20(4):528698. https://doi.org/10.3390/molecules20045286.

7. Ventola $\mathrm{CL}$. The antibiotic resistance crisis: part 1: causes and threats. P T. 2015:40(4):277-83.

8. Antibiotic Resistance Threats [https://www.cdc.gov/drugresistance/pdf/threa ts-report/2019-ar-threats-report-508.pdf].

9. Antimicrobial resistance: tackling a crisis for the health and wealth of nations [https://amr-review.org/sites/default/files/160525_Final\%20paper_ with\%20cover.pdf]. 
10. Gandra S, Barter D, Laxminarayan R. Economic burden of antibiotic resistance: how much do we really know? Clin Microbiol Infect. 2014;20(10): 973-9. https://doi.org/10.1111/1469-0691.12798.

11. Founou RC, Founou LL, Essack SY. Clinical and economic impact of antibiotic resistance in developing countries: a systematic review and metaanalysis. PLoS One. 2017;12(12):e0189621. https://doi.org/10.1371/journal. pone.0189621.

12. Atif M, Asghar S, Mushtaq I, Malik I. Community pharmacists as antibiotic stewards: a qualitative study exploring the current status of antibiotic stewardship program in Bahawalpur, Pakistan. J Infect Public Health. 2019

13. Atif $M$, Azeem $M$, Saqib A, Scahill S. Investigation of antimicrobial use at a tertiary care hospital in southern Punjab, Pakistan using WHO methodology. Antimicrob Resist Infect Control. 2017;6(1):41. https://doi.org/10.1186/s13 756-017-0199-7

14. Atif M, Malik I, Asif M, Qamar-Uz-Zaman M, Ahmad N, Shane Scahill: Drug Safety in Pakistan. In: Al-Worafi Y, editor. Drug Safety in Developing Countries. India: Elsevier; 2020. p. 287-316.

15. Malik I, Atif M, Riaz F, Asghar S, Ahmad N. Pediatric antibiotic pack size compliance with the dosage regimen: a descriptive study. Ther Innov Regul Sci. 2020;54(3):492-506. https://doi.org/10.1007/s43441-019-00081-7.

16. Atif M, Ahmad W, Ahmad N, Malik I, Sarwar S. Treatment outcomes among multidrug-resistant TB patients in Bahawal Victoria Hospital, Bahawalpur, Pakistan: a retrospective record review. Trans R Soc Trop Med. 2020;114(10): 733-41. https://doi.org/10.1093/trstmh/traa040.

17. Goff DA, Kullar R, Goldstein EJC, Gilchrist M, Nathwani D, Cheng AC, et al. A global call from five countries to collaborate in antibiotic stewardship: united we succeed, divided we might fail. Lancet Infect Dis. 2017;17(2):e5663. https://doi.org/10.1016/S1473-3099(16)30386-3.

18. Van Dijck C, Vlieghe E, Cox JA. Antibiotic stewardship interventions in hospitals in low-and middle-income countries: a systematic review. Bull World Health Organ. 2018;96(4):266-80. https://doi.org/10.2471/BLT.17.20344 8.

19. Pierce J, Apisarnthanarak A, Schellack N, Cornistein W, Maani AA, Adnan S, et al. Global antimicrobial stewardship with a focus on low- and middleincome countries. Int J Infect Dis. 2020;96:621-9. https://doi.org/10.1016/j. ijid.2020.05.126.

20. Saleem Z, Hassali MA. Travellers take heed: outbreak of extensively drug resistant (XDR) typhoid fever in Pakistan and a warning from the US CDC. Travel Med Infect Dis. 2019;27:127. https://doi.org/10.1016/j.tmaid.2018.10. 013.

21. Saleem Z, Hassali MA, Hashmi FK, Godman B, Ahmed Z. Snapshot of antimicrobial stewardship programs in the hospitals of Pakistan: findings and implications. Heliyon. 2019;5(7):e02159. https://doi.org/10.1016/j. heliyon.2019.e02159.

22. Atif M, Asghar S, Mushtaq I, Malik I, Amin A, Babar Z-U-D, et al. What drives inappropriate use of antibiotics? A mixed methods study from Bahawalpur, Pakistan. Infect Drug Resist. 2019;12:687-99. https://doi.org/10.2147/IDR.S1 89114.

23. Atif M, Malik I, Asif M, Qamar-Uz-Zaman M, Ahmad N. scahill S: Drug safety in Pakistan. In: Al-Worafi Y, editor. Drug Safety in Developing Countries: Achievements and Challenges. India: Elsevier; 2020. p. 287-316.

24. The Medical Microbiology And Infectious Diseases Society Of Pakistan [http://www.mmidsp.com/].

25. Saleem Z, Hassali MA, Hashmi FK. Pakistan's national action plan for antimicrobial resistance: translating ideas into reality. Lancet Infect Dis. 2018; 18(10):1066-7. https://doi.org/10.1016/S1473-3099(18)30516-4.

26. Malik I, Atif M, Scahill SL. Babar ZU: Pharmacy Practice and Policy Research in Pakistan: A Review of Literature Between 2014 And 2019. In: ZUD. B, editor. Global Pharmaceutical Policy, vol. 2020. Singapore: Palgrave Macmillan. p. 139-75.

27. National Action Plan of Pakistan on Antimicrobial Resistance [https://www. nih.org.pk/wp-content/uploads/2018/08/AMR-National-Action-Plan-Pakistan. pdf].

28. Hayat K, Rosenthal M, Zhu S, Gillani AH, Chang J, Bogale AA, et al. Attitude of clinicians towards hospital-based antimicrobial stewardship programs: a multicenter cross-sectional study from Punjab, Pakistan. Expert Rev Anti-Infect Ther. 2019;17(8):661-9. https://doi.org/10.1080/14787210.2019.1647780.

29. Hayat $K$, Rosenthal M, Gillani AH, Zhai $P$, Aziz MM, Ji W, et al. Perspective of Pakistani physicians towards hospital antimicrobial stewardship programs: a multisite exploratory qualitative study. Int J Environ Res Public Health. 2019; 16(9):1565. https://doi.org/10.3390/ijerph16091565.
30. Saleem Z, Hassali MA, Godman B, Hashmi FK, Saleem F. Antimicrobial prescribing and determinants of antimicrobial resistance: a qualitative study among physicians in Pakistan. Int J Clin Pharm. 2019;41(5):1348-58. https:// doi.org/10.1007/s11096-019-00875-7.

31. Saleem Z, Hassali MA, Hashmi F, Azhar F, Hasan H, Zaheer S, et al. Assessment of physicians' perception about antibiotic use and resistance and factors influencing antibiotic prescribing: a situational analysis from Pakistan. Fam Med Prim Care Rev. 2019;21(2):149-57. https://doi.org/10. 5114/fmpcr.2019.84551.

32. Atif M, Ahmad M, Saleem Q, Curley L, Qamar-uz-Zaman M. Pharmaceutical policy in Pakistan. In: Pharmaceutical Policy in Countries with Developing Healthcare Systems: Springer; 2017. p. 25-44.

33. Atif M, Malik I. Why is Pakistan vulnerable to COVID-19 associated morbidity and mortality? A scoping review. Int J Health Plann Manag. 2020;35(5):104154. https://doi.org/10.1002/hpm.3016.

34. Economic Survey 2019-20 [http://www.finance.gov.pk/survey/chapter_20/ PES_2019_20.pdf].

35. Atif M, Sarwar MR, Azeem M, Umer D, Rauf A, Rasool A, et al. Assessment of WHO/INRUD core drug use indicators in two tertiary care hospitals of Bahawalpur, Punjab, Pakistan. J Pharm Policy Pract. 2016;9(1):27. https://doi. org/10.1186/s40545-016-0076-4.

36. Creswell JW, Creswell JD. Research design: qualitative, quantitative, and mixed methods approaches: sage publications; 2017.

37. Paré G, Kitsiou S. Methods for literature reviews. In: Handbook of eHealth Evaluation: An Evidence-based Approach [Internet]: University of Victoria; 2017.

38. Roberts K, Dowell A, Nie J-B. Attempting rigour and replicability in thematic analysis of qualitative research data; a case study of codebook development. BMC Med Res Methodol. 2019;19(1):66. https://doi.org/10.11 86/s12874-019-0707-y.

39. Tongco MDCJER, applications. Purposive sampling as a tool for informant selection, vol. 5; 2007. p. 147-58.

40. Morse JM. Determining sample size. Thousand Oaks, CA: Sage Publications Sage CA; 2000.

41. Saunders B, Sim J, Kingstone T, Baker S, Waterfield J, Bartlam B, et al. Saturation in qualitative research: exploring its conceptualization and operationalization. Qual Quant. 2018;52(4):1893-907. https://doi.org/10.1007/ s11135-017-0574-8.

42. Atif M, Malik I, Mushtaq I, Asghar S. Medicines shortages in Pakistan: a qualitative study to explore current situation, reasons and possible solutions to overcome the barriers. BMJ Open. 2019;9(9):e027028. https://doi.org/1 0.1136/bmjopen-2018-027028.

43. Fereday J, Muir-Cochrane E. Demonstrating rigor using thematic analysis: a hybrid approach of inductive and deductive coding and theme development. Int J Qual Methods. 2006;5(1):80-92. https://doi.org/10.1177/1 60940690600500107.

44. Ezzy D. Qualitative analysis. London: Routledge; 2013. https://doi.org/1 $0.4324 / 9781315015484$.

45. Silverman D. Qualitative research. London: Sage Publications Ltd; 2016.

46. Tong A, Sainsbury P, Craig J. Consolidated criteria for reporting qualitative research (COREQ): a 32-item checklist for interviews and focus groups. Int J Qual Health Care. 2007;19(6):349-57. https://doi.org/10.1093/intqhc/ mzm042.

47. Jinks T, Lee N, Sharland M, Rex J, Gertler N, Diver M, et al. A time for action: antimicrobial resistance needs global response. Bull World Health Organ. 2016;94(8):558-558A. https://doi.org/10.2471/BLT.16.181743.

48. Global action plan on antimicrobial resistance [http://www.who.int/a ntimicrobial-resistance/global-action-plan/en].

49. Boucher HW, Bakken JS, Murray BE. The United Nations and the urgent need for coordinated global action in the fight against antimicrobial ResistanceCoordinated global action to fight against antimicrobial resistance. Ann Intern Med. 2016;165(11):812-3. https://doi.org/10.7326/M1 6-2079.

50. Cabana MD, Rand CS, Powe NR, Wu AW, Wilson MH, Abboud PA, et al. Why don't physicians follow clinical practice guidelines? A framework for improvement. JAMA. 1999;282(15):1458-65. https://doi.org/10.1001/jama.2 82.15.1458,

51. Om C, Daily F, Vlieghe E, McLaughlin JC. McLaws M-L: "if it'sa broad spectrum, it can shoot better": inappropriate antibiotic prescribing in Cambodia. Antimicrob Resist Infect Control. 2016;5(1):58. https://doi.org/1 0.1186/s13756-016-0159-7. 
52. Hashemi S, Nasrollah A, Rajabi M. Irrational antibiotic prescribing: a local issue or global concern? EXCLI J. 2013;12:384-95.

53. File TM Jr, Solomkin JS, Cosgrove SE. Strategies for improving antimicrobial use and the role of antimicrobial stewardship programs. Clin Infect Dis. 2011;53(suppl_1):S15-22.

54. Tamma PD, Avdic E, Li DX, Dzintars K, Cosgrove SE. Association of adverse events with antibiotic use in hospitalized patients. JAMA Int Med. 2017; 177(9):1308-15. https://doi.org/10.1001/jamainternmed.2017.1938.

55. Kotwani A, Wattal C, Katewa S, Joshi PC, Holloway K. Factors influencing primary care physicians to prescribe antibiotics in Delhi India. Fam Pract. 2010;27(6):684-90. https://doi.org/10.1093/fampra/cmq059.

56. Nair M, Tripathi S, Mazumdar S, Mahajan R, Harshana A, Pereira A, et al. "Without antibiotics, I cannot treat": A qualitative study of antibiotic use in Paschim Bardhaman district of West Bengal, India. PLoS One. 2019;14(6).

57. Tillekeratne LG, Bodinayake CK, Dabrera T, Nagahawatte A, Arachchi WK, Sooriyaarachchi A, et al. Antibiotic overuse for acute respiratory tract infections in Sri Lanka: a qualitative study of outpatients and their physicians. BMC Fam Pract. 2017;18(1):37. https://doi.org/10.1186/s12875-01 7-0619-z.

58. Fletcher-Lartey S, Yee M, Gaarslev C, Khan R. Why do general practitioners prescribe antibiotics for upper respiratory tract infections to meet patient expectations: a mixed methods study. BMJ Open. 2016;6(10).

59. Beović B, Doušak M, Pulcini C, Béraud G, Paño Pardo JR, Sánchez-Fabra D, et al. Young doctors' perspectives on antibiotic use and resistance: a multinational and inter-specialty cross-sectional European Society of Clinical Microbiology and Infectious Diseases (ESCMID) survey. J Antimicrob Chemother. 2019;74(12):3611-8. https://doi.org/10.1093/jac/dkz375.

60. Al-Homaidan HT, Barrimah IE. Physicians' knowledge, expectations, and practice regarding antibiotic use in primary health care. Int J Health Sci. 2018;12(3):18-24.

61. De Souza V, MacFarlane A, Murphy AW, Hanahoe B, Barber A, Cormican M. A qualitative study of factors influencing antimicrobial prescribing by nonconsultant hospital doctors. J Antimicrob Chemother. 2006;58(4):840-3. https://doi.org/10.1093/jac/dkl323.

62. Cook PP, Catrou PG, Christie JD, Young PD, Polk RE. Reduction in broadspectrum antimicrobial use associated with no improvement in hospital antibiogram. J Antimicrob Chemother. 2004;53(5):853-9. https://doi.org/10.1 093/jac/dkh163.

63. Aly NY, Omar AA, Badawy DA, Al-Mousa HH, Sadek AA. Audit of physicians' adherence to the antibiotic policy guidelines in Kuwait. Med Princ Pract. 2012;21(4):310-7. https://doi.org/10.1159/000334769.

64. Brinkmann I, Kibuule D. Effectiveness of antibiotic stewardship programmes in primary health care settings in developing countries. Res Soc Adm Pharm. 2020;16(9):1309-13. https://doi.org/10.1016/j.sapharm.2019.03.008.

65. Antimicrobial stewardship - a competency-based approach [https:// openwho.org/courses/AMR-competency].

\section{Publisher's Note}

Springer Nature remains neutral with regard to jurisdictional claims in published maps and institutional affiliations.

Ready to submit your research? Choose BMC and benefit from:

- fast, convenient online submission

- thorough peer review by experienced researchers in your field

- rapid publication on acceptance

- support for research data, including large and complex data types

- gold Open Access which fosters wider collaboration and increased citations

- maximum visibility for your research: over $100 \mathrm{M}$ website views per year

At BMC, research is always in progress.

Learn more biomedcentral.com/submissions 